\title{
QUEEN'S
UNIVERSITY
BELFAST
}

\section{Enhancing community pharmacists' provision of medication adherence support to older adults: A mixed methods study using the Theoretical Domains Framework}

Patton, D. E., Ryan, C., \& Hughes, C. M. (2021). Enhancing community pharmacists' provision of medication adherence support to older adults: A mixed methods study using the Theoretical Domains Framework. Research in Social and Administrative Pharmacy, 17(2), 406-418. https://doi.org/10.1016/j.sapharm.2020.03.004

Published in:

Research in Social and Administrative Pharmacy

Document Version:

Peer reviewed version

Queen's University Belfast - Research Portal:

Link to publication record in Queen's University Belfast Research Portal

\section{Publisher rights}

Copyright 2020 Elsevier.

This manuscript is distributed under a Creative Commons Attribution-NonCommercial-NoDerivs License

(https://creativecommons.org/licenses/by-nc-nd/4.0/), which permits distribution and reproduction for non-commercial purposes, provided the author and source are cited.

\section{General rights}

Copyright for the publications made accessible via the Queen's University Belfast Research Portal is retained by the author(s) and / or other copyright owners and it is a condition of accessing these publications that users recognise and abide by the legal requirements associated with these rights.

\section{Take down policy}

The Research Portal is Queen's institutional repository that provides access to Queen's research output. Every effort has been made to ensure that content in the Research Portal does not infringe any person's rights, or applicable UK laws. If you discover content in the

Research Portal that you believe breaches copyright or violates any law, please contact openaccess@qub.ac.uk. 
1

2 support to older adults: a mixed methods study using the Theoretical

\section{Domains Framework}

\section{Abstract}

\section{Background}

6 Community pharmacists have an important role to play in providing medication adherence support

7 (MAS) to older patients. However, research has shown that pharmacists rarely ask patients about

8 adherence and offer limited solutions. The Theoretical Domains Framework (TDF) can guide the

9 selection of behaviour change techniques (BCTs), to enhance behaviours such as MAS provision.

10 Objectives

11 This study aimed to: (1) explore barriers/facilitators influencing community pharmacists' provision of MAS to older patients prescribed multiple medications; (2) Identify theoretical domains to target for behaviour change; (3) Select BCTs to deliver to pharmacists to enhance MAS provision.

Method

As part of a two-phase study, semi-structured interviews and a cross-sectional survey were conducted. In Phase 1, community pharmacists in Northern Ireland (NI) were recruited using purposive/snowball sampling. TDF-based interviews were audio-recorded, transcribed and analysed by two independent researchers using the framework method/content analysis. In Phase 2, a TDFbased postal survey was mailed to all community pharmacies in $\mathrm{NI}(n=521)$ and analysed using descriptive statistics. Triangulated findings informed selection of target TDF domains and BCTs to deliver to enhance MAS provision.

Results

Fifteen pharmacists were interviewed for Phase 1. Barriers and facilitators included inadequate remuneration, time and knowledge of solutions and professional confidence. In Phase 2, 143 (27.4\%) survey responses were received. Potential barriers included inadequate training in motivational techniques and difficulties with decision-making. Based on triangulated findings, seven domains (e.g. skills, memory) were identified as targets and mapped across to 18 BCTs (e.g. behavioural practice/rehearsal, prompts/cues). 
29 Conclusions

30 This mixed methods study provides unique perspectives on the wide range of barriers/facilitators

31 that are perceived to influence the provision of MAS by community pharmacists. The 18 BCTs

32 identified to target each of the seven key target domains identified in this study will be tested in a

33 future pilot study of a patient-targeted intervention.

34 Keywords

35 Medication adherence, community pharmacists, mixed methods, behaviour change, polypharmacy,

36 theoretical domains framework 
Medication non-adherence is common in patients prescribed several medications (polypharmacy), with older patients at particular risk due to high levels of multi-morbidity in this population group. Interventions to improve medication adherence commonly focus on patients' behaviour but healthcare professionals (HCPs) have a key role to play in supporting patients. Community pharmacists, in particular, are ideally placed to support older patients due to their frequency of contact when patients collect repeat prescriptions. There is growing recognition that in addition to targeting patients' adherence behaviour directly, it is important to consider the behaviours required of those who are responsible for supporting patients and delivering interventions to improve adherence. $^{1-3}$ The 2003 World Health Organisation (WHO) report recognised that community pharmacists require training in both assessing patients who are at potential risk of non-adherence, and in the delivery of interventions to improve it. ${ }^{1}$ Guidance from the UK National Institute for Health and Care Excellence (NICE) also describes the provision of medication adherence support (MAS) as a complex clinical behaviour, consisting of both identifying non-adherent patients and providing tailored interventions. ${ }^{2}$ To date, there has been limited research into exactly what helps and hinders community pharmacists in providing MAS to older patients. ${ }^{3}$ Preliminary qualitative and quantitative research has shown that potential barriers include inadequate time, lack of confidence and patient resistance. ${ }^{4-8}$ In the context of Northern Ireland, the extent to which community pharmacists identify non-adherent older patients and provide tailored adherence support is currently unclear. Services currently offered in Northern Ireland, such as the Medicine Use Review service, lack a clear structure with regards to improving medication adherence, and their effectiveness in improving adherence and cost-effectiveness currently remains unknown..$^{9,10}$

It is also important to consider community pharmacists' training requirements and potential implementation barriers, such as environmental constraints in the community pharmacy setting, which may impact on MAS provision as recommended in the NICE guidance. ${ }^{2}$ The UK Medical Research Council (MRC) recommends that complex interventions, including training packages, should be systematically developed to maximise effectiveness and gain an understanding of their proposed mechanism of action. The Theoretical Domains Framework (TDF) is a theoretical framework which can act as a 'theoretical lens' to explore HCPs' clinical behaviours and gain a more comprehensive understanding of the key influences of that behaviour (i.e. the barriers and facilitators). ${ }^{11}$ The 12 domain framework was developed by a group of psychologists and health service researchers to overcome challenges 
change theories into the following domains: 'Knowledge', 'Skills', 'Social/professional role and identity', 'Beliefs about capabilities', 'Beliefs about consequences', 'Motivation and goals', 'Memory, attention and decision processes', 'Environmental context and resources' and 'Social influences'. The TDF can be used to identify exactly what aspects (i.e. domains) should be targeted to bring about change in the behaviour. Key target domains that contain potential barriers and facilitators to the performance of the behaviour are then selected as intervention targets. For example, in this context the domain 'Knowledge' might be selected if pharmacists were unaware of the range of adherence solutions available. Selected key TDF domains can then be mapped to strategies known as behaviour change techniques (BCTs) using established methods reported in the literature. ${ }^{12,13}$ BCTs are defined as "...the smallest components of behaviour change interventions that on their own in favourable circumstances can bring about change." and these can form part of training packages or other implementation strategies to enhance implementation of the desired behaviour. ${ }^{14}$

This mixed methods study reported here aimed to: (1) Explore determinants (i.e. barriers and facilitators) that influence community pharmacists' provision of MAS to older patients who are prescribed multiple medicines using TDF-based qualitative interviews and a quantitative questionnaire; (2) Identify exactly what could be targeted to change pharmacists' behaviour and select key TDF domains to target; (3) Select BCTs to deliver as part of a training package and implementation strategies to include in future research studies to enhance pharmacists' provision of MAS.

\section{Methods}

\section{Rationale for a mixed methods approach}

The majority of TDF-based studies have adopted qualitative approaches to explore the behaviour in question and identify barriers and facilitators to behaviour change. ${ }^{15}$ However, mixed methods approaches $^{16-18}$ are increasingly being used as triangulated qualitative and quantitative findings can provide a more complete picture of the behaviour under question. ${ }^{19}$ The current study therefore adopted a mixed methods approach to explore community pharmacists' provision of MAS using indepth qualitative interviews with community pharmacists (Phase 1 ), followed by a quantitative survey (Phase 2). There are currently two versions of the TDF- a 12 domain (TDF1) $)^{11}$ and 14 domain version (TDF2). ${ }^{20}$ TDF1 ${ }^{11}$ was selected as the theoretical framework of choice for this mixed methods study. This decision was supported by a discriminant content validity exercise undertaken by Huijq et al. ${ }^{21}$ which recommended 'keeping to the 12 original domains as a basis for the development of TDF questionnaires'. Ethical approval for the study was granted by XXXXX. Phase 1 of this study has been reported in line with the 'Consolidated criteria for reporting qualitative studies' (COREQ) checklist 
which aims to ensure comprehensive reporting of qualitative methods ${ }^{22}$ (see Supplementary file 1). The specific methods employed for Phase 1 and Phase 2 of the study are detailed below.

\section{Phase 1: Semi-structured interviews}

TDF-based semi-structured qualitative interviews were selected to gain an initial in-depth understanding of the target behaviour (provision of MAS to older adults prescribed polypharmacy). Interviews were selected over focus groups as they were deemed a more cost-effective and convenient approach for the target audience.

\section{Sampling and recruitment}

To be eligible for inclusion in this study, pharmacists had to be currently working in a registered community pharmacy in Northern Ireland. Community pharmacists who had previously taken part in a prior linked feasibility study of a patient-targeted intervention ${ }^{23}$ were not eligible to participate. A purposive sampling strategy was selected to allow for the inclusion of a variety of pharmacists working in different locations and types of pharmacies (e.g. independently-owned pharmacies and chains). The initial sampling frame included community pharmacies $(n=164)$ who were part of the XXXX undergraduate community pharmacy placement network. A snowball sampling approach was also used, whereby recruited participants from the network identified other potentially information-rich individuals. ${ }^{24}$ To aid the identification of data saturation, preliminary data analysis and collection ran concurrently. The researcher (XX) initially contacted community pharmacists from the sampling frame via telephone to invite them to participate in Phase 1. Formal invitation letters and study information sheets were mailed/e-mailed to those expressing an interest and pharmacists were given five working days to make a decision about participation. The sample size was determined by data saturation which was achieved when no new themes were emerging. ${ }^{25}$

\section{Interview topic guide}

A semi-structured interview topic guide (supplementary file 2), based on TDF1 ${ }^{11}$, was developed by the research team. Examples of questions included: 'What skills do you currently have as a community pharmacist that would enable you to provide medication adherence support to an older adult who is prescribed polypharmacy?' (Domain: Skills); 'To what extent is providing medication adherence support to older adults prescribed polypharmacy a priority for you?' (Domain: Motivation and goals). The topic guide was piloted with two researchers from XXXXXX who were practising in the community pharmacy setting at the time of the study. Minor refinements were made based on feedback from pilot participants (e.g. wording changes). 


\section{Conduct of interviews}

Face-to-face interviews took place at a location and time that was convenient for both the researcher and pharmacist (e.g. pharmacy site, local cafe). The researcher (XX, MPharm, PhD Research Student at the time of the study/practising community pharmacist) had previous experience with qualitative research and had completed training on qualitative research methodologies. Interviews were conducted between August and November 2016. Prior to participation, pharmacists provided written informed consent and demographic details (e.g. years qualified) were collected. To account for the time allocated to this study, participants were offered an honorarium of $£ 50$ and a certificate of participation.

All interviews were audio-recorded and transcribed verbatim with participants' consent. Each participant was assigned a unique identification number (e.g. CP01). Transcripts were checked for accuracy prior to importing into NVivo ${ }^{\circledR}$ QSR 11 . All study documents were stored either in a locked fire-resistant filing cabinet or on a password protected laptop.

\section{Quality of qualitative methods}

The use of multiple independent data coders and a clear audit trail of all decisions made (facilitated by the use of $\mathrm{NVivo}^{\circledR}$ ) aimed to ensure dependability of the findings (a concept whereby the same results would be obtained if the study were to be repeated). Triangulation of the qualitative findings with quantitative findings aimed to ensure credibility of the results (i.e. the extent to which such results are believable). The use of the COREQ checklist also helped to ensure transparency of the methods used and the findings (see completed checklist in Supplementary file 1).

\section{Phase 2: Cross-sectional survey}

\section{Questionnaire design}

For Phase 2, a self-administered postal survey was selected over an electronic survey due to the low response rates commonly seen with the latter and lack of access to individual email addresses. ${ }^{26,27}$ The questionnaire (see Supplementary file 3 ) was developed based on findings from the qualitative interviews (Phase 1), similar literature, ${ }^{6,8,28,29}$ and with reference to the domains in TDF1. ${ }^{11}$

The questionnaire contained three sections with Section 1 focusing on demographics. In Section 2, respondents were asked about MAS activities they engaged with in their own practice on a five-point scale (very frequently to never/not at all). Section 3 focused on potential determinants of providing MAS and explored the domains in TDF1. The 'Nature of behaviours' domain (defined as 'essential characteristics of the behaviour' $)^{30}$ which has been described as a dependent variable, rather than an independent variable was assessed in Section 2 and so was excluded from Section 3. Example survey 
items in Section 3 included: 'I receive sufficient reimbursement for providing MAS to older patients' (Domain: Motivation and goals); 'I have sufficient knowledge of the range of adherence strategies that are available to support older patients' (Domain: Knowledge).

Barriers/facilitators were assessed at the domain level as it was deemed impractical to measure individual theoretical constructs as domains contained between 4-24 constructs each. Responses to items within Section 3 were based on a five-point Likert scale (strongly agree to strongly disagree) and were assigned to each TDF domain $(n=11)$ using a group consensus approach. This method reflected approaches used in the development of previous TDF-based questionnaires. ${ }^{31-34}$ Where possible, Likert items $(n=21)$ were adapted from previous TDF-based questionnaires. ${ }^{31,32,34-36}$ To ensure relevance to the target behaviour, a number of new items $(n=17)$ were developed based on Phase 1 qualitative findings and non-TDF based questionnaires in the literature related to medication adherence. ${ }^{6,8}$

For example the item 'I have sufficient pharmacist staff levels to allow me to provide medication adherence support to older patients' was developed based on the qualitative findings in Phase 1 (See Supplementary File 3). Open style questions were included in Sections 2 and 3 to identify any additional MAS activities and barriers or facilitators.

\section{Face validity and piloting}

Face validity of the questionnaire was assessed by three members of the research team who had previous experience with using TDF1. Items assigned to each theoretical domain were assessed to determine whether they appeared on the surface to measure what they were intended to measure. The questionnaire was also piloted with five pharmacists from XXXXX who had current $(n=4)$ or previous experience $(n=1)$ of working in the community pharmacy setting. The aim of this was to ensure the readability and acceptability of questionnaire items and to help estimate the time required for completion. Following pilot testing, minor amendments were made to questions (e.g. ambiguous items were reworded).

\section{Sampling and recruitment}

The target population for the questionnaire was community pharmacists working in the region of Northern Ireland. Addresses for all pharmacy premises registered in Northern Ireland the time of the study ( $n=548$ ) were obtained from the Pharmaceutical Society of Northern Ireland (PSNI). Twenty seven pharmacies were excluded from the sampling frame because they had participated in Phase 1 of this study $(n=14)$, took part in a previous linked feasibility study $(n=2)$, were based in a hospital $(n=10)$ or based in a prison $(n=1) .{ }^{23}$ An invitation letter (addressed to the pharmacist in charge), questionnaire and freepost return envelope were posted to the 521 community pharmacies remaining 
199 in the sampling frame. Participation in the study was voluntary, responses were anonymous and 200 informed consent was implicit upon returning the questionnaire.

201 Response rate and non-response bias

202 To maximise the response rate, a reminder copy of the questionnaire was posted four weeks after the 203 first mailing to all pharmacies (responses were anonymous so non-responders could not be identified). 204 Following a low response rate with the first mailing, the research protocol was amended and ethical 205 approval was sought to promote the questionnaire via relevant social media outlets (e.g. Twitter). To 206 detect non-response bias, demographic data collected from respondents was compared with data 207 available for all pharmacists on the PSNI register which included pharmacists in all sectors (e.g. 208 community, hospital, industry).

\section{Questionnaire data management}

210 Returned questionnaires were assigned a unique identifier number and responses were entered into 211 SPSS (IBM Corp. Released 2016. IBM SPSS Statistics for Windows, Version 24.0. Armonk, NY: IBM 212 Corp.). Missing responses were coded accordingly. A random 10\% sample was double-checked for 213 input accuracy. This detected a low inaccuracy rate of $0.23 \%$ which was deemed to be acceptable. 214 Qualitative responses were entered into Microsoft Word 2016.

215 Data analysis of interviews and questionnaires

216 Data analysis for the current study consisted of three key stages which have been summarised in 217 Figure 1. 
Stage 1: Identification of determinants of MAS provision

$\begin{gathered}\text { Stage 1a: Qualitative analysis } \\ \text { (interviews) }\end{gathered}$
-Transcription of audio-recordings
-Familiarisation process
-Framework analyis (TDF1 as
theoretical framework)
-Content analysis (barriers and
facilitators identified)

Stage 2: Identification of key TDF domains to target

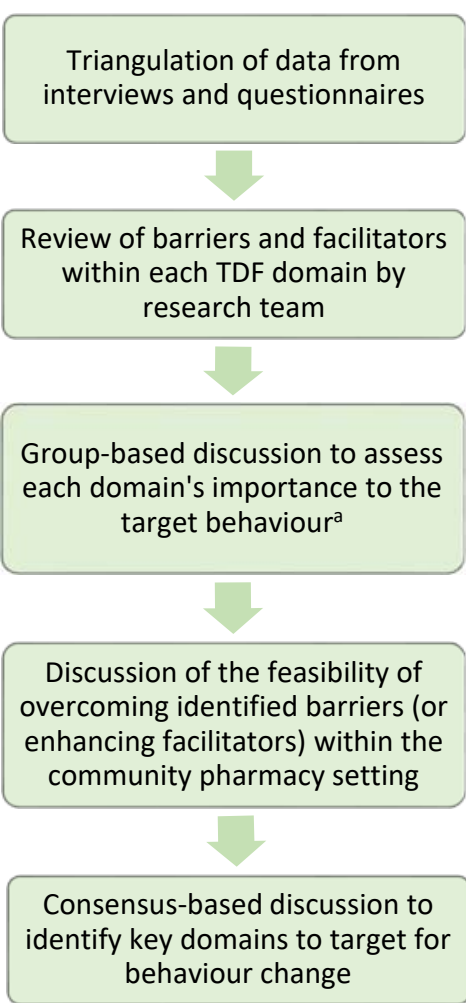

Stage 3: Selection of BCTs to enhance MAS provision

Key TDF domains mapped to BCTs usin primary ${ }^{\mathrm{b}}$ reference source ${ }^{13}$

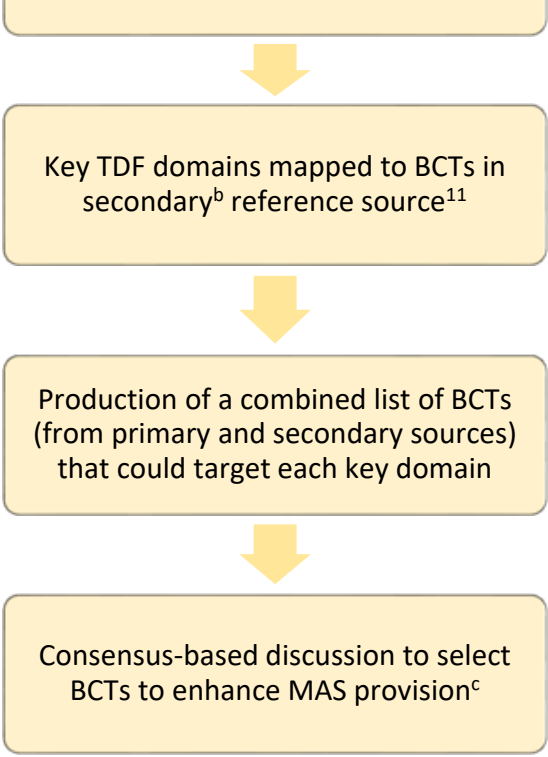

Key: TDF= Theoretical Domains Framework; BCT= Behaviour change technique; MAS= Medication adherence support

Figure 1: An overview of the three stages involved in data analysis

${ }^{a}$ A domain was considered important if it was frequently coded as part of the qualitative analysis and/or it contained items that reflected potential barriers/facilitators to the target behaviour based on the quantitative analysis; ${ }^{b}$ No BCTs mapped to 'Memory, attention and decision processes' and 'Social/professional role and identity' domains in the primary reference source hence the secondary reference source was also consulted; ' Selection of BCTs was based on the expected feasibility of BCT delivery as part of a community pharmacist training package (or as implementation strategies in future research studies) and applicability to the target behaviour and audience 
Stage 1a: Identification of determinants of MAS provision from interviews

Following transcription of the interview audio-recordings, an in-depth familiarisation process was undertaken with repeated reading of transcripts. For the framework analysis each of the 12 domains in TDF1 served as coding categories. ${ }^{37}$ Inductive content analysis was then undertaken to identify emergent barriers and facilitators within each TDF domain which were discussed and agreed upon by the research team. Each transcript was independently coded by two researchers and any disagreements were resolved through discussion.

\section{Stage 1b: Identification of determinants of MAS provision from the survey}

Descriptive statistical analyses were conducted for Section 1 (demographics) and Section 2 (experiences of providing MAS). Responses from open-style questions were qualitatively analysed for emergent themes. In Section 3 (determinants of MAS provision), descriptive statistical analyses were employed to explore the proportion of pharmacists in agreement or disagreement with each Likert item $(n=37)$. In some cases, Likert item scores can be combined to produce a summative scale score (e.g. items around a particular personality trait). ${ }^{38}$ However, before combining items it is important to ensure they are measuring the same thing. Cronbach's alpha $(\alpha)$ on a scale of 0 to 1 is commonly used to assess internal consistency with higher scores indicating greater similarities between items. ${ }^{39} \mathrm{An} \alpha$ value above 0.6 can be deemed sufficient for scaling multiple Likert items, whereas an $\alpha$ value below 0.6 indicates that the items are potentially measuring different concepts or theoretical constructs. ${ }^{40}$ Alternatively, the Likert items can be analysed individually as ordinal-type questions. ${ }^{38,41,42}$ Likert items in each TDF domain in this study were not combined into a scale as $\alpha$ values were less than 0.6 for six out of the 11 TDF domains assessed. For consistency in data analysis, Likert items were assessed individually within all domains. Individual responses to Likert items was assigned an integer, from strongly agree $=1$ to strongly disagree $=5$, and the median value was calculated as a measure of central tendency. ${ }^{43}$ Higher median scores of 4 or 5 indicated more disagreement with the statement, highlighting a potential barrier. TDF domains containing at least one potential barrier were identified as possible targets for behaviour change.

\section{Stage 2: Triangulation of findings and identification of key TDF domains}

Key findings from Phases 1 and 2 were listed together to explore similarities and differences. ${ }^{19}$ The research team discussed potential barriers identified within each domain and used the frequency of interview coding in Phase 1 as a crude measure of the domains importance. Domains containing potential barriers identified from the quantitative analysis in Phase 2 were also considered when assessing the importance of each TDF domain in the context of the target behaviour. A domain was subsequently deemed important if it was frequently coded in the qualitative analysis and/or the findings from the quantitative analysis indicated potential barrier(s) within the domain. 
Although a domain can be deemed important to the behaviour it may not be feasible to target the barriers, or enhance the facilitators further, with an intervention. Using group consensus, the team selected domains that contained barriers that could feasibly be overcome, or facilitators that could be enhanced, either as part of a training package and/or using implementation strategies that could be employed as part of future research studies (e.g. incentives, reminders). These selected domains were termed 'key domains'.

\section{Stage 3: Mapping of Key TDF domains to BCTS}

Key domains were then mapped across to BCTs using methods originally developed by Michie et al. ${ }^{11}$ and updated more recently by Cane et al. ${ }^{13}$ All potential BCTs that mapped to each domain were considered and BCTs were selected using a group consensus approach which was informed by the triangulated findings from Phases 1 and 2. When selecting BCTs the research team considered the applicability of each BCT to the target behaviour and audience. Potential difficulties with delivering $\mathrm{BCTs}$, as part of a training workshop and/or as implementation strategies were taken into consideration at this stage. For example, delivery of the BCT 'Motivational interviewing' would require specialised training which may not be feasible in this context.

\section{Results}

\section{Summary of findings from Phase 1 (Interviews)}

\section{Interview participant characteristics}

Fifteen pharmacists (7 females) took part in qualitative interviews between August and November 2016. Participants had been registered with the PSNI for an average of 14.1 years (range 1-31 years). A small minority of pharmacists $(n=3)$ had additional pharmacy qualifications (e.g. Clinical Diploma). Pharmacists from rural $(n=7)$ and urban $(n=8)$ areas were recruited including those working in independently-owned pharmacies $(n=7)$, small/medium chains with 2-9 stores $(n=3)$ and large chains with $10+$ stores $(n=5)$. Pharmacist roles included proprietors $(n=3)$, managers $(n=8)$ and non-managers (e.g. support pharmacist) $(n=4)$. Six pharmacists had received training on MAS and only two had participated in previous research/service evaluations on MAS in the five years prior. Interviews lasted between 30 to 72 minutes (average 46 minutes). Data saturation was reached by the fifteenth interview as no new themes were emerging.

\section{Identification of determinants of MAS from interviews (Stage 1a results)}

Pharmacists reported a wide range of barriers and facilitators that influenced the provision of MAS. The barriers and facilitators identified within each TDF domain are summarised in Table 1 together with illustrative quotes. 


\begin{tabular}{|c|c|c|}
\hline Domain & $\begin{array}{l}\text { Determinants (barriers, facilitator) of community pharmacists' } \\
\text { provision of MAS }\end{array}$ & Illustrative quotes \\
\hline Knowledge & $\begin{array}{l}\text { - Knowledge (facilitator) or lack of knowledge (barrier) of } \\
\text { - Knedications/products/medical conditions } \\
\text { non-adherence (facilitator) } \\
\text { - Knowledge of patients (e.g. social background, medical } \\
\text { history) (facilitator) } \\
\text { - Knowledge (facilitator) or lack of knowledge (barrier) of } \\
\text { adherence problems and solutions }\end{array}$ & $\begin{array}{l}\text { "So there's the pharmaceutical knowledge and then I think just the community knowledge } \\
\text { and background knowledge of knowing the patients and knowing their family set-up and, } \\
\text { em, knowing their level of education..." (CP13) } \\
\text { "I think we're, we're fairly aware of the... issues that are out there in terms of adherence." } \\
\text { (СP03) } \\
\text { "...And giving them (community pharmacists), sort of, even ideas that, that they could use } \\
\text { within the pharmacy to help, help with the patients. And not just the simple Mediboxes... } \\
\text { which are so time-consuming." (CP07) } \\
\text { "...you're not going to give someone medication adherence sup- advice if you don't really } \\
\text { know- if, you know, that you don't have obviously that, like, em, knowledge." (CP05) }\end{array}$ \\
\hline Skills & $\begin{array}{l}\text { - } \quad \text { Communication skills (e.g. listening, questioning) (facilitator) } \\
\text { - } \text { Skills (facilitator) or lack of skills (barrier) required to } \\
\text { - } \text { motivate/persuade older patients to adhere } \\
\text { - } \quad \text { Time management and problem solving skills (delegation, } \\
\text { - } \quad \text { organisational skills) (facilitator) } \\
\text { - } \quad \text { Lack of consultation skills (e.g. reviews, follow-ups) (barrier) }\end{array}$ & $\begin{array}{l}\text { "...communication skills is one of the most important ones to be able to converse with the } \\
\text { patient. Em, and, eh, ask, sorry questions, so questioning skills, listening skills, everything } \\
\text { within communication." (CP13) } \\
\text { "...any type of training where you're, sort of, giving people ideas of how, how to approach } \\
\text { people and just what way to speak with them, it's - I think it would be good." (CP07) } \\
\text { "There's a skill that would be needed, is how to actually instigate a review, how to, you } \\
\text { know, get something happening, but then to actually come back and review it..." (CP09) } \\
\text { Aw we try... are my persuasion skills that good? Sometimes yes but it can-... you do in } \\
\text { ways with different people, and it's back to the some of the people some of the time..." } \\
\text { (CP11) }\end{array}$ \\
\hline $\begin{array}{l}\text { Social, professional } \\
\text { role and identity }\end{array}$ & $\begin{array}{l}\text { - Important role to play in providing MAS including referral, } \\
\text { - } \quad \text { liaison and social care roles (facilitator) } \\
\text { - Unable to prescribe as part of current role (barrier) } \\
\text { - } \quad \text { Professional responsibility to support adherence (facilitator) } \\
\text { - Isolated role/not integrated into primary care team (barrier) } \\
\text { - Role unrecognised by others (e.g. patients, commissioners, } \\
\text { - GPs) (barrier) } \\
\text { - Roles of pharmacy support staff [e.g. preparing Monitored } \\
\text { dosage systems (MDS), identifying non-adherent patients] } \\
\text { (facilitator) }\end{array}$ & $\begin{array}{l}\text { "In terms of their adherence with medication you are the last person in that chain before } \\
\text { the medicine arrives with the patient. Em, so you- I suppose you have ultimate } \\
\text { responsibility for understanding why they're taking their medicines and how they should } \\
\text { be taken." (CP15) } \\
\text { "...if there was something that I thought it wasn't- it was beyond my responsibility I } \\
\text { would still try and refer them to whoever... it was. Em, obviously like I can't change their } \\
\text { tablets over to something else but I, I can refer them on to the GP who can..." (CP01) } \\
\text { "...the only potential problem I see is one, perception... of the public that this is our role." } \\
\text { (CP09) }\end{array}$ \\
\hline
\end{tabular}




\begin{tabular}{|c|c|c|}
\hline $\begin{array}{l}\text { Beliefs about } \\
\text { capabilities }\end{array}$ & 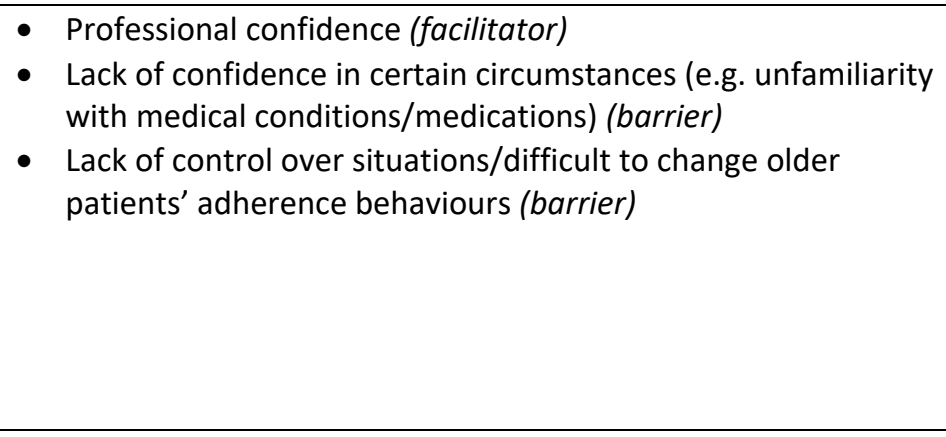 & $\begin{array}{l}\text { "..when you say confident you, you, yeah you'd be confident to carry out the role..." } \\
\text { (CP01) } \\
\text { "...perhaps if it is some- you would even, medication itself, if you're not overly familiar } \\
\text { with it, maybe could make you feel maybe a bit less confident about, em, dealing with any } \\
\text { issues." (CP03) } \\
\text { "I would like more training in, in engaging patients, you know, em, but I think a lot of it is } \\
\text { down to confidence, you know, and em, but the MURs [Medicine Use Review Service] } \\
\text { have definitely helped with that..." (CP15) } \\
\text { "Trying to break their determination down (laughs) 'cause once they have an idea in their } \\
\text { head, it's very difficult to get them to move." (CP04) }\end{array}$ \\
\hline $\begin{array}{l}\text { Beliefs about } \\
\text { consequences }\end{array}$ & $\begin{array}{l}\text { - Beliefs about potential positive outcomes (e.g. improved } \\
\text { clinical outcomes, cost savings, fewer GP visits and hospital } \\
\text { admissions) (facilitator) } \\
\text { - Beliefs about personal gain (e.g. job satisfaction, increased } \\
\text { respect) (facilitator) } \\
\text { - Beliefs that providing MAS improves the profile of } \\
\text { community pharmacy (facilitator) } \\
\text { - Beliefs about potential costs and impact on time (barrier) } \\
\text { - } \text { when adherence improves (barrier) }\end{array}$ & $\begin{array}{l}\text { "I think there could be a financial benefit but also I think just a health benefit for people, } \\
\text { em, and just ensuring that they're getting the best out of their medication." (CP02) } \\
\text { "...just personal gain in, like, eh, more- increased respect and maybe, like, that would } \\
\text { come probably with more opportunities..." (CP05) } \\
\text { "...You'd definitely - if you get a positive outcome it makes you feel good about your job." } \\
\text { (CP10) } \\
\text { "'cause once someone is non-adherent and then becomes adherent, potential is there } \\
\text { that they could actually get really unwell. Because they're not taking them as directed as } \\
\text { before, then suddenly they're taking them and... somethings too strong..." (CP12) }\end{array}$ \\
\hline Motivation and goals & $\begin{array}{l}\text { - High intrinsic motivation (i.e. high personal priority) } \\
\text { (facilitator) } \\
\text { - Motivated by potential benefits to patients (e.g. improved } \\
\text { clinical outcomes) (facilitator) } \\
\text { - Lower priority than other pharmacy activities (e.g. } \\
\text { dispensing, other paid services) (barrier) } \\
\text { - Conflicting priorities (professional responsibility verses } \\
\text { commercial priorities) (barrier) } \\
\text { - Proprietors/owners largely motivated by financial rewards } \\
\text { (barrier) } \\
\text { - Employees less motivated by financial rewards (facilitator) } \\
\text { - Prioritising high risk patients/medications (e.g. those with } \\
\text { limited social support, patients taking warfarin) } \\
\text { (facilitator)/(barrier) }\end{array}$ & $\begin{array}{l}\text { "Very high priority yeah, very important, very important." (CP08) } \\
\text { "Em, no I think it comes down to more than money. I think it's a service we have to } \\
\text { provide, whether we get paid for it or not..." (CP04) } \\
\text { "I wouldn't say it's a priority at the minute... the priority would be patients who you look } \\
\text { at and you see them going downhill or they're not coping with their medication..." (CP02) } \\
\text { "... we've a delicate balance between the commercial realities of having to keep } \\
\text { customers happy and telling people this is what's good for you, you have to do it, you } \\
\text { don't want to alienate people." (CP06) } \\
\text { "...the contractors, you would probably want some sort of a remuneration for it." (CP14) } \\
\text { "...directly I'm not a contractor so I don't get paid per MUR [Medicine Use Review]... I get } \\
\text { paid to go in and do a day's work, what that-a day's work entails... it doesn't really make } \\
\text { a difference to me. (CP15) }\end{array}$ \\
\hline
\end{tabular}




\begin{tabular}{|c|c|c|}
\hline $\begin{array}{l}\text { Memory, attention } \\
\text { and decision } \\
\text { processes }\end{array}$ & $\begin{array}{l}\text { - Difficult to remember (barrier) } \\
\text { - Decisions tailored to individual patients (facilitator) } \\
\text { - Involvement of patients, carers and other HCPs in decisions } \\
\text { (facilitator) } \\
\text { - Lack of structured approach to aid decisions (barrier) }\end{array}$ & $\begin{array}{l}\text { "... without a formal assessment tool at the minute, em, it's done very much on an } \\
\text { individual basis..." (CP06) } \\
\text { "Well the patient's response to the questions or to the proposed interventions, em... so } \\
\text { whether they would- whether a change would make any difference. Em, whether the GP } \\
\text { buys into the change as well or the prescriber..." (CP15) } \\
\text { "I think, you need some system that will highlight it, otherwise you see so many people, so } \\
\text { many things that yeah some you might remember but no you wouldn't consistently } \\
\text { remember." (CP02) }\end{array}$ \\
\hline $\begin{array}{l}\text { Environmental } \\
\text { context and } \\
\text { resources }\end{array}$ & $\begin{array}{l}\text { - Time constraints due to heavy workload (barrier) } \\
\text { - Currently funded services (MUR, MYM) (facilitator) } \\
\text { - No service focusing specifically on adherence (barrier) } \\
\text { - Accessibility of community pharmacy (facilitator) } \\
\text { - Presence of multiple pharmacists (facilitator) } \\
\text { - Inadequate pharmacist staff levels (barrier) } \\
\text { - Adequate pharmacy support staff (levels, competency) } \\
\text { - } \text { (facilitator) } \\
\text { - } \text { - Patient.co.uk) (facilitator) } \\
\text { - Inadequate space (barrier) } \\
\text { - Lack of integration in primary healthcare team (barrier) } \\
\text { - Lack of access to full medication history (ECR) (barrier) } \\
\end{array}$ & $\begin{array}{l}\text { "But pharmacies like to say time is a problem-we don't have time to do anything. } \\
\text { (Laughs) No I think time is the only one but you would just fit it in-just one of those } \\
\text { things." (CPO4) } \\
\text { "....the only thing that puts me off is time, you know, pharmacy's got busier and busier..." } \\
\text { (CP15) } \\
\text { "...well I suppose just MURs [Medicine Use Review Service] and medicines management } \\
\text { [Managing Your Medicines Service] would help, you know, would help identify the } \\
\text { problems." (CP01) } \\
\text { "So if I'm not integrated within a team, then there's, there's only so much I can actually } \\
\text { do..." (CP09) } \\
\text { "So I think, em, even having access to maybe the ECR [Electronic Care Record] or } \\
\text { something like that where we could see exactly what sort of prescriptions have been... } \\
\text { processed and, and that kind of thing would help to sort of establish if there was any } \\
\text { issues." (CP03) }\end{array}$ \\
\hline Social influences & 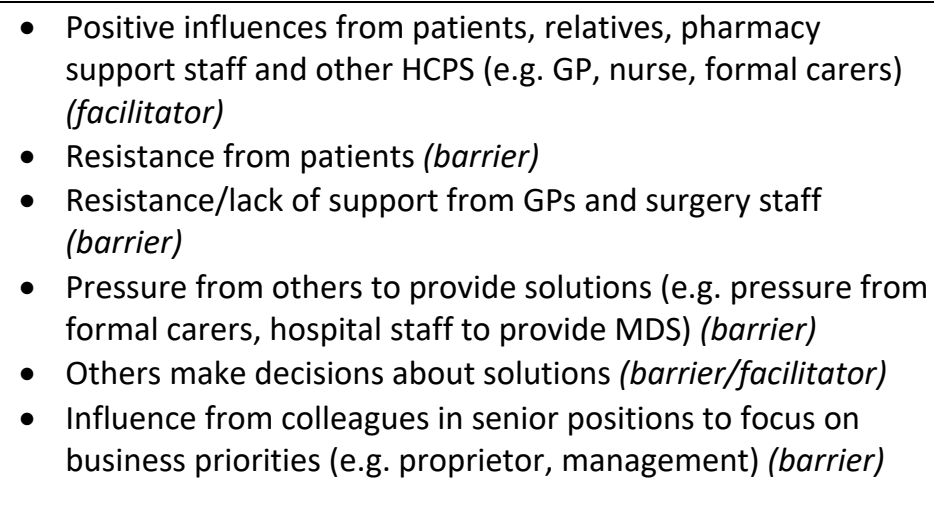 & $\begin{array}{l}\text { "All of our patients have either been referred by doctors, by carers, by relatives." (CP11) } \\
\text { "Some patients, no matter what you say to them or how much you try and you try to talk } \\
\text { to them about something, just don't want to know." (CPO1) } \\
\text { "...for whatever reason the powers that be, be it the family, the doctors, the carers- } \\
\text { 'cause the carers completely refuse to deal with medication if it's not in a blister pack } \\
\text { [Monitored Dosage System]" (CP04) } \\
\text { "Sometimes you can, you can, reach a bit of a, not loggerheads but you're kind of having } \\
\text { problems with maybe getting onto a surgery, trying to get stuff sorted and you're getting } \\
\text { resistance there." (CP12) } \\
\text { "...obviously, like, you're working for a company- would be, like, patients but your other, } \\
\text { like, staff obviously, like, my, like, manager would have like a huge say in that and, em, } \\
\text { like, what... we need to focus on, like in any kind of business..." (CP05) }\end{array}$ \\
\hline
\end{tabular}




\begin{tabular}{|c|c|c|}
\hline Emotion & $\begin{array}{l}\text { - Positive affect (i.e. encouraged)(facilitator) } \\
\text { - } \quad \text { Worried about providing incorrect advice (barrier) } \\
\text { - Stress due to time constraints (barrier) }\end{array}$ & $\begin{array}{l}\text { "You feel like you're helping somebody so you feel like you're, you're doing good so yeah } \\
\text { it does make you feel good, if it, if it works out." (CPO1) } \\
\text { "It makes you feel good, that you're actually doing something of benefit... and that } \\
\text { they're getting the best... that they can get." (CPO4) } \\
\text { "I suppose a bit of a fear thing isn't it like? Where, you're afraid of saying the wrong } \\
\text { thing..." (CP12) }\end{array}$ \\
\hline $\begin{array}{l}\text { Behavioural } \\
\text { regulation }\end{array}$ & $\begin{array}{l}\text { - } \text { Reactive behaviour (i.e. not proactive in identifying and } \\
\text { supporting patients) (barrier) } \\
\text { - } \quad \text { Lack of formalised procedures (i.e. no standard operating } \\
\text { procedures or framework currently in use) (barrier) } \\
\text { - } \text { Record-keeping (e.g. on PMR) (facilitator) } \\
\text { - Positive feedback from patients (facilitator) } \\
\text { - } \text { Reminder systems as moderators of intention-behaviour gap } \\
\text { (e.g. diary, notes on PMR) (facilitator) } \\
\text { - Monitoring patients' adherence behaviour (e.g. frequency of } \\
\text { dispensing using PMR) }\end{array}$ & $\begin{array}{l}\text { "Speaking to the patient would probably be one of the main ones, seeing are they } \\
\text { happier, you know. Do they feel like things have improved?" (CP01) } \\
\text { "I suppose with their PMRs [Patient Medication Records] we've an opportunity to } \\
\text { highlight sort of things on it... and throw up messages that maybe, you know, you can } \\
\text { check back with them the next time..." (CP02) } \\
\text { "...you'd like to assume that people's following the directions and taking their medication } \\
\text { as is, until that problem is identified. So maybe, potentially it might be something more } \\
\text { proactive that we could do." (CP12) }\end{array}$ \\
\hline $\begin{array}{l}\text { Nature of the } \\
\text { behaviours }\end{array}$ & $\begin{array}{l}\text { Direct experience through provision of funded services (e.g. } \\
\text { MUR, MYM services) (facilitator) } \\
\text { - Identification of non-adherent patients is not routine } \\
\text { (barrier) } \\
\text { - Most routine activity is the supply of MDS (barrier) }\end{array}$ & $\begin{array}{l}\text { "Em... there's nothing that l'd routinely do I suppose it would be coming from, like, the } \\
\text { patient themselves." (CP05) } \\
\text { "I think the current trend would be medidose boxes [Monitored Dosage System]... you } \\
\text { know, if somebody's having difficulty taking their tablets, put it in a medidose box but I've } \\
\text { seen people do strange things with medidose boxes once they get them (Laughs)." (CP15) } \\
\text { "... we're kind of already doing it with our smoking cessation and our MURs [Medicine } \\
\text { Use Review service], you know, Medicines Management [Managing Your Medicines } \\
\text { Service], things like that." (CP12) }\end{array}$ \\
\hline
\end{tabular}


286

287

288

289

290

291

292

293

294

295

296

297

298

299

300

301

302

303

304

305

306

307

308

309

310

311

312

313

314

315

316

\section{Survey participant characteristics}

In total, 143 questionnaires were returned giving a response rate of $27.4 \%$. Eighty-two respondents were female (57.3\%), which was marginally under-representative as $68.1 \%$ of pharmacists on the PSNI register were female. Respondents had been practising an average of 15.3 (SD: \pm 11.2 ) years and $63.7 \%$ survey respondents were aged 44 years or under, compared with $68.1 \%$ of all pharmacists on the PSNI register who were aged 40 years or under. Fifty-nine respondents $(41.3 \%)$ worked for a large chain (10+ stores), 40 respondents (28.0\%) worked for a small/medium chain (2-9 stores) and 41 respondents $(28.7 \%)$ worked at an independently-owned pharmacy. Pharmacists also reported working across a range of locations including rural (30.1\%), suburban $(22.4 \%)$ and urban $(45.5 \%)$ areas. Further demographic data including information on staffing characteristics, service provision and training can be found in Supplementary file 4 .

\section{Survey participants' experiences of providing medication adherence support}

In Section 2 of the survey, less than half of the respondents reported very frequent or frequent use of pharmacy held-records (44.8\%) or return of unused medications (41.3\%) as methods for identifying non-adherent older patients. Only a third of pharmacists (33.6\%) reported very frequently or frequently asking older patients about missed doses. Less than a third of pharmacists (30.1\%) reported very frequently or frequently exploring the underlying reasons for older patients' non-adherence.

Just over half of the respondents (55.3\%) reported that they very frequently or frequently considered options to improve adherence in discussion with older patients and just over a third (38.5\%) reported very frequently or frequently tailoring adherence support strategies to the underlying reasons for nonadherence. Adherence solutions that were most frequently employed (i.e. more than $70 \%$ of pharmacists reported very frequent or frequent provision) included: prescription collection services (93.7\%), supply of Monitored Dosage Systems (MDS) at the request of others (88.1\%), support/reassurance/encouragement (79.7\%), prescription ordering services (76.2\%) and deliveries to patients' homes $(70.6 \%)$. Adherence solutions that were employed least frequently (i.e. less than $30 \%$ of pharmacists reported very frequent or frequent provision) included: techniques to increase motivation such as goal-setting or action plans (12.6\%), requesting changes to medications/regimens (21\%), provision of alternative packaging $(27.3 \%)$, recommendations to purchase adherence aids (27.3\%) and recommendation of self-monitoring strategies (e.g. diary, calendar) (29.4\%) The full results of Section 2 can be found in Supplementary file 5. Only a few additional adherence strategies were reported by respondents including: synchronising medications so that they could all be ordered 
at one time, home visits, colour coding time slots on MDS and asking patients to return MDS packaging to check adherence before providing a new supply.

320 The proportion of respondents that agreed or disagreed with each Likert item in Section 3 of the

321 questionnaire is displayed in Table 2. Six out of the 36 items analysed had high medians (of 4 or 5 )

322 indicating disagreement with the statement and highlighting potential barriers to the behaviour.

323 These six items had been assigned a priori to four TDF domains: 'Skills', 'Environmental context and

324 resources', 'Memory, attention and decision processes' and 'Motivation and goals'. The Likert item,

325 'Others (e.g. GPs, carers) decide which adherence support strategies are required by older patients,

326 was excluded from the analysis as it could be either a barrier or a facilitator depending on the

327 appropriateness of the recommendations made by others. No additional barriers were identified in

328 the open-style question in Section 3. 
Table 2: Community pharmacists' responses to Likert items within each TDF domain (Phase 2: survey) (items in bold denote identified barriers to providing MAS)

\begin{tabular}{|c|c|c|c|c|c|c|c|c|c|}
\hline TDF domain & Likert-items assigned to each TDF domain & $\begin{array}{l}\text { Strongly } \\
\text { agree } \mathrm{N} \\
\text { (\%) } \\
\text { (score:1) }\end{array}$ & $\begin{array}{l}\text { Agree } N \\
(\%) \\
\text { (score:2) }\end{array}$ & $\begin{array}{l}\text { Neither } \\
\text { agree nor } \\
\text { disagree } \mathrm{N} \\
(\%) \\
\text { (Score:3) }\end{array}$ & $\begin{array}{l}\text { Disagree } \\
\mathbf{N}(\%) \\
\text { (Score:4) }\end{array}$ & $\begin{array}{l}\text { Strongly } \\
\text { disagree } \\
\mathrm{N}(\%) \\
\text { (score:5) }\end{array}$ & $\begin{array}{l}\text { Missing } \\
\text { responses } \\
\text { N (\%) }\end{array}$ & $\begin{array}{l}\text { Median } \\
\text { score for } \\
\text { item } \\
(\text { IQR) }\end{array}$ & $\begin{array}{l}\text { Potential target } \\
\text { for behaviour } \\
\text { change }\end{array}$ \\
\hline \multirow[t]{3}{*}{ Knowledge } & $\begin{array}{l}\text { I know how to provide MAS to older patients in line } \\
\text { with NICE guidance }\end{array}$ & $14(9.8)$ & $77(53.8)$ & $36(25.2)$ & $12(8.4)$ & $3(2.1)$ & $1(0.7)$ & $\begin{array}{l}2.0(2.0- \\
3.0)\end{array}$ & \multirow{3}{*}{$\begin{array}{l}\text { No } \\
\text { (no items with } \\
\text { high medians in } \\
\text { this domain) }\end{array}$} \\
\hline & $\begin{array}{l}\text { I know the appropriate questions to ask older patients } \\
\text { to determine underlying reasons for non-adherence }\end{array}$ & $16(11.2)$ & $87(60.8)$ & $26(18.2)$ & $12(8.4)$ & $1(0.7)$ & $1(0.7)$ & $\begin{array}{l}2.0(2.0- \\
3.0)\end{array}$ & \\
\hline & $\begin{array}{l}\text { I have sufficient knowledge of the range of adherence } \\
\text { strategies that are available to support older patients }\end{array}$ & $14(9.8)$ & $67(46.9)$ & $32(22.4)$ & 27 (18.9) & $2(1.4)$ & $1(0.7)$ & $\begin{array}{l}2.0(2.0- \\
3.0)\end{array}$ & \\
\hline \multirow[t]{3}{*}{ Skills } & $\begin{array}{l}\text { I have been trained to provide MAS to older patients in } \\
\text { line with NICE guidance }\end{array}$ & $11(7.7)$ & $33(23.1)$ & $45(31.5)$ & $44(30.8)$ & $9(6.3)$ & $1(0.7)$ & $\begin{array}{l}3.0(2.0- \\
4.0)\end{array}$ & \multirow{3}{*}{$\begin{array}{l}\text { Yes (domain } \\
\text { contains an } \\
\text { item with high } \\
\text { median) }\end{array}$} \\
\hline & $\begin{array}{l}\text { I have the communication skills required to provide } \\
\text { MAS to older patients }\end{array}$ & $38(26.6)$ & $89(62.2)$ & $13(9.1)$ & $1(0.7)$ & $0(0)$ & $2(1.4)$ & $\begin{array}{l}2.0(1.0- \\
2.0)\end{array}$ & \\
\hline & $\begin{array}{l}\text { I do not require additional training on techniques that } \\
\text { can be used to increase older patients' motivation to } \\
\text { adherence }^{b}\end{array}$ & $3(2.1)$ & $12(8.5)$ & $31(21.7)$ & $71(49.7)$ & $24(16.8)$ & $2(1.4)$ & $\begin{array}{l}4.0(3.0- \\
4.0)^{1}\end{array}$ & \\
\hline \multirow{3}{*}{$\begin{array}{l}\text { Social, } \\
\text { professional } \\
\text { role and } \\
\text { identity }\end{array}$} & $\begin{array}{l}\text { Providing MAS to older patients is part of my current } \\
\text { role as a community pharmacist }\end{array}$ & $34(23.8)$ & $86(60.1)$ & $17(11.9)$ & $2(1.4)$ & $2(1.4)$ & $2(1.4)$ & $\begin{array}{l}2.0(2.0- \\
2.0)\end{array}$ & \multirow{3}{*}{$\begin{array}{l}\text { No } \\
\text { (no items with } \\
\text { high medians in } \\
\text { this domain) }\end{array}$} \\
\hline & It is my responsibility to provide MAS to older patients & $22(15.4)$ & $83(58.0)$ & $29(20.3)$ & $7(4.9)$ & $1(0.7)$ & $1(0.7)$ & $\begin{array}{l}2.0(2.0- \\
3.0)\end{array}$ & \\
\hline & $\begin{array}{l}\text { Older patients consider the provision of MAS to be } \\
\text { part of my role as a community pharmacist }\end{array}$ & $10(7.0)$ & $52(36.4)$ & $56(39.2)$ & $22(15.4)$ & $1(0.7)$ & $2(1.4)$ & $\begin{array}{l}3.0(2.0- \\
3.0)\end{array}$ & \\
\hline \multirow[t]{4}{*}{$\begin{array}{l}\text { Beliefs about } \\
\text { capabilities }\end{array}$} & $\begin{array}{l}\text { I find it easy to discuss medication adherence with } \\
\text { older patients }^{\mathrm{b}}\end{array}$ & $15(10.5)$ & $88(61.5)$ & 27 (18.9) & $9(6.3)$ & $3(2.1)$ & $1(0.7)$ & $\begin{array}{l}2.0(2.0- \\
3.0)\end{array}$ & \multirow{4}{*}{$\begin{array}{l}\text { No } \\
\text { (no items with } \\
\text { high medians in } \\
\text { this domain) }\end{array}$} \\
\hline & $\begin{array}{l}\text { I am confident that I can address any medication } \\
\text { adherence problems that I encounter with older } \\
\text { patients }\end{array}$ & $20(14.0)$ & $96(67.1)$ & $20(14.0)$ & $6(4.2)$ & $0(0)$ & $1(0.7)$ & $\begin{array}{l}2.0(2.0- \\
2.0)\end{array}$ & \\
\hline & $\begin{array}{l}\text { I am confident that I can provide MAS to older patients } \\
\text { even when they are not motivated }\end{array}$ & $13(9.1)$ & $82(57.3)$ & $28(19.6)$ & $19(13.3)$ & $0(0)$ & $1(0.7)$ & $\begin{array}{l}2.0(2.0- \\
3.0)\end{array}$ & \\
\hline & $\begin{array}{l}\text { I am confident that I can provide MAS to older patients } \\
\text { even when I am unfamiliar with their medical } \\
\text { conditions }\end{array}$ & $10(7.0)$ & $58(40.6)$ & $37(25.9)$ & $34(23.8)$ & $3(2.1)$ & $1(0.7)$ & $\begin{array}{l}3.0(2.0- \\
4.0)\end{array}$ & \\
\hline
\end{tabular}




\begin{tabular}{|c|c|c|c|c|c|c|c|c|c|}
\hline \multirow[t]{3}{*}{$\begin{array}{l}\text { Beliefs about } \\
\text { consequences }\end{array}$} & $\begin{array}{l}\text { Providing MAS to older patients improves the profile } \\
\text { of community pharmacy }\end{array}$ & $53(37.1)$ & $75(52.4)$ & $11(7.7)$ & $1(0.7)$ & $1(0.7)$ & $2(1.4)$ & $\begin{array}{l}2.0(1.0- \\
2.0)\end{array}$ & \multirow{3}{*}{$\begin{array}{l}\text { No } \\
\text { (no items with } \\
\text { high medians in } \\
\text { this domain) }\end{array}$} \\
\hline & $\begin{array}{l}\text { Providing MAS to older patients leads to health } \\
\text { benefits for patients and cost-savings for the NHS }\end{array}$ & $65(45.5)$ & $67(46.9)$ & $6(4.2)$ & $0(0)$ & $1(0.7)$ & $4(2.8)$ & $\begin{array}{l}2.0(1.0- \\
2.0)\end{array}$ & \\
\hline & $\begin{array}{l}\text { Providing MAS to older patients gives me job } \\
\text { satisfaction }\end{array}$ & $51(35.7)$ & $80(55.9)$ & $10(7.0)$ & $1(0.7)$ & $0(0)$ & $1(0.7)$ & $\begin{array}{l}2.0(1.0- \\
2.0)\end{array}$ & \\
\hline \multirow[t]{5}{*}{$\begin{array}{l}\text { Motivation } \\
\text { and goals }\end{array}$} & $\begin{array}{l}\text { Seeing the benefits of providing MAS to older patients } \\
\text { helps me to overcome barriers such as lack of time } \\
\text { and reimbursement }\end{array}$ & $16(11.2)$ & $46(32.2)$ & $53(37.1)$ & $20(14.0)$ & $7(4.9)$ & $1(0.7)$ & $\begin{array}{l}3.0(2- \\
3.0)\end{array}$ & \multirow{5}{*}{$\begin{array}{l}\text { Yes (domain } \\
\text { contains an } \\
\text { item with a } \\
\text { high median) }\end{array}$} \\
\hline & $\begin{array}{l}\text { Providing MAS to older patients is a high priority for } \\
\text { me in my daily practice }{ }^{b}\end{array}$ & $13(9.1)$ & $66(46.2)$ & $43(30.1)$ & $18(12.6)$ & $2(1.4)$ & $1(0.7)$ & $\begin{array}{l}2.0(2.0- \\
3.0)\end{array}$ & \\
\hline & $\begin{array}{l}\text { I want to support more older patients with medication } \\
\text { adherence in the future }\end{array}$ & $41(28.7)$ & 90 (62.9) & $8(1.4)$ & $2(1.4)$ & $1(0.7)$ & $1(0.7)$ & $\begin{array}{l}2.0(1.0- \\
2.0)\end{array}$ & \\
\hline & It is important to always offer MAS to older patients & $39(27.3)$ & $85(59.4)$ & $17(11.9)$ & $1(0.7)$ & $0(0)$ & $1(0.7)$ & $\begin{array}{l}2.0(1.0- \\
2.0)\end{array}$ & \\
\hline & $\begin{array}{l}\text { I receive sufficient reimbursement for providing MAS } \\
\text { to older patients }\end{array}$ & $2(1.4)$ & $6(4.2)$ & $25(17.5)$ & $53(37.1)$ & $56(39.2)$ & $1(0.7)$ & $\begin{array}{l}4.0^{1}(4.0- \\
5.0)\end{array}$ & \\
\hline \multirow{2}{*}{$\begin{array}{l}\text { Memory, } \\
\text { attention and } \\
\text { decision } \\
\text { processes }\end{array}$} & Providing MAS is easy for me to remember & $4(2.8)$ & $35(24.5)$ & $72(50.3)$ & $29(20.3)$ & $2(1.4)$ & $1(0.7)$ & $\begin{array}{l}3.0(2.0- \\
3.0)\end{array}$ & \multirow{2}{*}{$\begin{array}{l}\text { Yes (domain } \\
\text { contains an } \\
\text { item with high } \\
\text { median) }\end{array}$} \\
\hline & $\begin{array}{l}\text { Deciding on the best adherence support strategy for } \\
\text { older patients is easy }\end{array}$ & $2(1.4)$ & $11(7.7)$ & $30(21.0)$ & $92(64.3)$ & $6(4.2)$ & $2(1.4)$ & $\begin{array}{l}4.0^{1}(3.0- \\
4.0)\end{array}$ & \\
\hline \multirow{5}{*}{$\begin{array}{l}\text { Environmental } \\
\text { context and } \\
\text { resources }\end{array}$} & $\begin{array}{l}\text { I have sufficient pharmacist staff levels to allow me } \\
\text { to provide MAS to older patients }\end{array}$ & $10(7.0)$ & $35(24.5)$ & $18(12.6)$ & $53(37.1)$ & $26(18.2)$ & $1(0.7)$ & $\begin{array}{l}4.0^{1}(2.0- \\
4.0)\end{array}$ & \multirow{5}{*}{$\begin{array}{l}\text { Yes (domain } \\
\text { contains items } \\
\text { with high } \\
\text { medians) }\end{array}$} \\
\hline & $\begin{array}{l}\text { I have sufficient non-pharmacist staff levels to allow } \\
\text { me to provide MAS to older patients }\end{array}$ & $8(5.6)$ & 47 (32.9) & $26(18.2)$ & $40(28.0)$ & $21(14.7)$ & $1(0.7)$ & $\begin{array}{l}3.0(2.0- \\
4.0)\end{array}$ & \\
\hline & $\begin{array}{l}\text { I have sufficient space in the pharmacy to allow me to } \\
\text { provide MAS to older patients }\end{array}$ & $29(20.3)$ & 57 (39.9) & $22(15.4)$ & $20(14.0)$ & $14(9.8)$ & $1(0.7)$ & $\begin{array}{l}2.0(2.0- \\
3.0)\end{array}$ & \\
\hline & $\begin{array}{l}\text { I have enough time to provide MAS to older } \\
\text { patients }^{\text {b }}\end{array}$ & $5(3.5)$ & $15(10.5)$ & $36(25.2)$ & $59(41.3)$ & $26(18.2)$ & $2(1.4)$ & $\begin{array}{l}4.0^{1}(3.0- \\
4.0)\end{array}$ & \\
\hline & $\begin{array}{l}\text { Lack of access to patients medical notes is not a } \\
\text { barrier to providing MAS }\end{array}$ & $2(1.4)$ & $11(7.7)$ & $20(14.0)$ & $62(43.4)$ & $47(32.9)$ & $1(0.7)$ & $\begin{array}{l}4.0^{1}(4.0- \\
5.0)\end{array}$ & \\
\hline
\end{tabular}




\begin{tabular}{|c|c|c|c|c|c|c|c|c|c|}
\hline \multirow[t]{4}{*}{$\begin{array}{l}\text { Social } \\
\text { influences }\end{array}$} & $\begin{array}{l}\text { Colleagues in senior positions support me in providing } \\
\text { adherence support to older patients }\end{array}$ & $5(3.5)$ & 31 (21.7) & 47 (32.9) & $44(30.8)$ & $14(9.8)$ & $1(0.7)$ & $\begin{array}{l}3.0(2-0- \\
4.0)\end{array}$ & \multirow{4}{*}{$\begin{array}{l}\text { No } \\
\text { (no items with } \\
\text { high medians in } \\
\text { this domain) }\end{array}$} \\
\hline & $\begin{array}{l}\text { I do not face resistance from GPs when trying to } \\
\text { provide } M A S^{\text {b }}\end{array}$ & $9(6.3)$ & $54(37.8)$ & $33(23.1)$ & $35(24.5)$ & $11(7.7)$ & $1(0.7)$ & $\begin{array}{l}3.0(2.0- \\
3.0)\end{array}$ & \\
\hline & $\begin{array}{l}\text { I do not face resistance from patients when trying to } \\
\text { provide } M^{b}{ }^{b}\end{array}$ & $8(5.6)$ & $60(42.0)$ & $43(30.1)$ & $31(21.7)$ & $0(0)$ & $1(0.7)$ & $\begin{array}{l}3.0(2.0- \\
3.0\end{array}$ & \\
\hline & $\begin{array}{l}\text { Others (e.g. GPs, carers) decide which adherence } \\
\text { support strategies are required by older patients }{ }^{c}\end{array}$ & $19(13.3)$ & $63(44.1)$ & $38(26.6)$ & $19(13.3)$ & $2(1.4)$ & $2(1.4)$ & $\begin{array}{l}2.0(2.0- \\
3.0)^{2}\end{array}$ & \\
\hline \multirow[t]{2}{*}{ Emotion } & $\begin{array}{l}\text { I do not worry about giving the wrong advice to older } \\
\text { patients when providing MAS }\end{array}$ & $14(9.8)$ & $65(45.5)$ & $39(27.3)$ & $23(16.1)$ & $1(0.7)$ & $1(0.7)$ & $\begin{array}{l}2.0(2.0- \\
3.0)\end{array}$ & \multirow{2}{*}{$\begin{array}{l}\text { No } \\
\text { (no items with } \\
\text { high medians in } \\
\text { this domain) }\end{array}$} \\
\hline & $\begin{array}{l}\text { I am comfortable talking to older patients about } \\
\text { medication adherence }{ }^{\mathrm{b}}\end{array}$ & $32(22.4)$ & $88(61.5)$ & $18(12.6)$ & $3(2.1)$ & $1(0.7)$ & $1(0.7)$ & $\begin{array}{l}2.0(2.0- \\
2.0)\end{array}$ & \\
\hline \multirow[t]{3}{*}{$\begin{array}{l}\text { Behavioural } \\
\text { regulation }\end{array}$} & $\begin{array}{l}\text { I try to be proactive by planning how I can identify and } \\
\text { support older patients with medication adherence }\end{array}$ & $7(4.9)$ & $48(33.6)$ & $42(29.4)$ & $40(28.0)$ & $5(3.5)$ & $1(0.7)$ & $\begin{array}{l}2.0(2.0- \\
4.0)\end{array}$ & \multirow{3}{*}{$\begin{array}{l}\text { No } \\
\text { (no items with } \\
\text { high medians in } \\
\text { this domain) }\end{array}$} \\
\hline & $\begin{array}{l}\text { I monitor and record the type of MAS that I provide to } \\
\text { older patients }\end{array}$ & $6(4.2)$ & $43(30.1)$ & $34(23.8)$ & $52(36.4)$ & $6(4.2)$ & $2(1.4)$ & $\begin{array}{l}3.0(2.0- \\
4.0)\end{array}$ & \\
\hline & $\begin{array}{l}\text { Receiving negative feedback from a patient regarding } \\
\text { adherence support advice would not prevent me from } \\
\text { offering this advice to others }{ }^{b}\end{array}$ & $15(10.5)$ & $82(57.3)$ & 25 (17.5) & $18(12.6)$ & $1(0.7)$ & $2(1.4)$ & $\begin{array}{l}2.0(2.0- \\
3.0)\end{array}$ & \\
\hline
\end{tabular}


330 Following comparison of the summary of findings from Phases 1 and 2, and discussion among

331 members of the research team, eight out of 12 domains were identified as important in the context

332 of the target behaviour: 'Knowledge', 'Skills', 'Social, professional role and identity', 'Motivation and

333 goals', 'Memory, attention and decision processes', 'Environmental context and resources', Social

334 influences' and 'Behavioural regulation'. Six of these domains were selected because they were

335 frequently coded in the qualitative analysis (listed in order of frequency): 'Environmental context and

336 resources', 'Motivation and goals', 'Social, professional role and identity', 'Social influences' 'Skills' and

337 'Knowledge'. All but two of these domains ('Knowledge', 'Social, professional role and identity') also

338 had had potential barriers identified in the quantitative analysis (Phase 2). In Phase 2, the 'Memory,

339 attention and decision processes' and 'Behavioural regulation' domains also revealed potential

340 barriers to the target behaviour and so were also selected as important to target for change.

341 Four domains were not frequently coded in the qualitative analysis and no potential barriers were

342 identified in the quantitative analysis (Phase 2). These domains were therefore not seen as important

343 in the context of the target behaviour: 'Beliefs about capabilities', 'Beliefs about consequences',

344 'Emotion', 'Nature of the behaviours'.

345 Out of the eight domains deemed important in the context of the target behaviour, seven of these

346 were considered to be key domains to target for behaviour change. The domain 'Social, professional

347 role and identity' was not selected for targeting as changing the role of community pharmacists was

348 deemed to be beyond the scope of this research.

349 Mapping of key TDF domains to BCTs (Stage 3 results)

350 The seven key domains identified in Stage 2 were mapped across to 39 BCTs which were considered

351 for inclusion in a training package or as implementation strategies in future research studies. ${ }^{12,13}$ Based

352 on group consensus-based discussion 18 BCTs were identified as suitable for inclusion - these are

353 presented in Table 3. Further detail regarding the reasons for selection (or non-selection) of BCTs are 354 provided in Supplementary File 6. 
Table 3: Final selection of BCTs to deliver to community pharmacists as part of a training package (or as implementation strategies) to enhance the provision of MAS

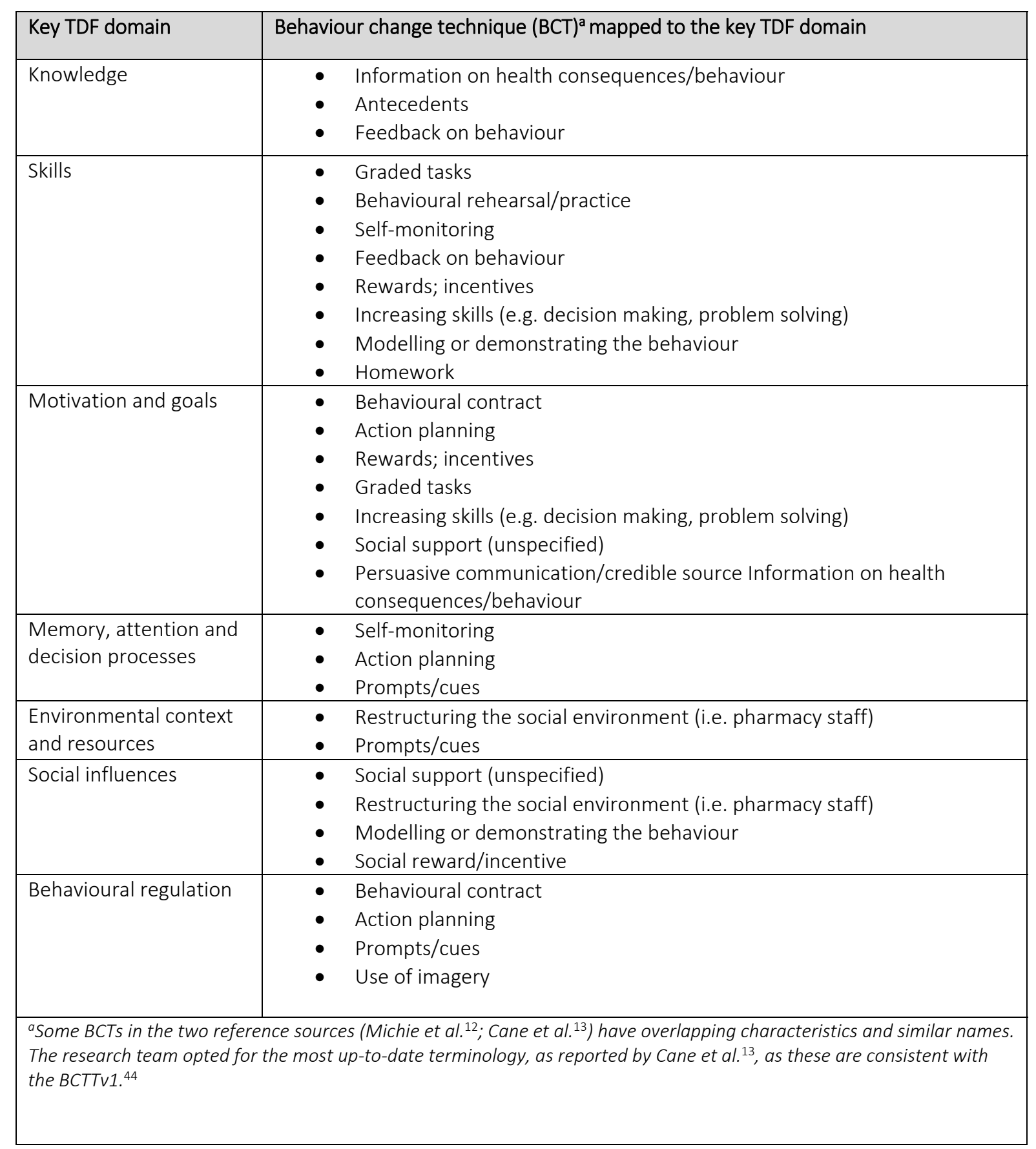


Table 4: Proposed delivery of BCTs as part of a training package and/or as implementation strategies to enhance MAS provision

\begin{tabular}{|c|c|c|c|}
\hline \multirow{2}{*}{$\begin{array}{l}\text { Behaviour change } \\
\text { technique (BCT) }\end{array}$} & \multicolumn{3}{|c|}{ How might the BCT be delivered to pharmacists to improve the provision of MAS? } \\
\hline & $\begin{array}{l}\text { Training } \\
\text { package }\end{array}$ & $\begin{array}{l}\text { Implementation } \\
\text { strategy }\end{array}$ & Example of how the BCT could be operationalised \\
\hline $\begin{array}{l}\text { Information on health } \\
\text { consequences/behaviour }\end{array}$ & $\checkmark$ & & Information about the behaviour and potential positive outcomes for patients could be presented. \\
\hline Antecedents & $\checkmark$ & & $\begin{array}{l}\text { Pharmacists could be provided information about the factors that can positively or negatively affect the } \\
\text { performance of the behaviour such as time, skills training etc. }\end{array}$ \\
\hline Feedback on behaviour & $\checkmark$ & $\checkmark$ & $\begin{array}{l}\text { Pharmacists could be given verbal feedback on their performance during practice sessions in a training } \\
\text { workshop or following the provision of MAS in the community pharmacy. }\end{array}$ \\
\hline Graded tasks & $\checkmark$ & & $\begin{array}{l}\text { Pharmacists could be set tasks to perform as part of training, ranging in complexity from easy to } \\
\text { difficult. }\end{array}$ \\
\hline $\begin{array}{l}\text { Behavioural } \\
\text { rehearsal/practice }\end{array}$ & $\checkmark$ & & $\begin{array}{l}\text { Pharmacists could practice performing the behaviour with patient actors as part of a training workshop } \\
\text { using role play scenarios. }\end{array}$ \\
\hline Self-monitoring & & $\checkmark$ & Pharmacists could record the number of patients they provided MAS to in a daily pharmacy tasks diary. \\
\hline Rewards; incentives & & $\checkmark$ & Small monetary rewards could be provided to encourage CPs to perform the target behaviour. \\
\hline $\begin{array}{l}\text { Increasing skills (e.g. } \\
\text { decision making, problem } \\
\text { solving) }\end{array}$ & $\checkmark$ & $\checkmark$ & $\begin{array}{l}\text { Pharmacists could be trained on how to decide on the best adherence solutions for older patients } \\
\text { during a training workshop. This could also be facilitated by a decision-making tool (e.g. web- } \\
\text { application) that maps adherence problems across to potential adherence solutions. }\end{array}$ \\
\hline $\begin{array}{l}\text { Modelling or } \\
\text { demonstrating the } \\
\text { behaviour }\end{array}$ & $\checkmark$ & & A training package could include video demonstrations of the target behaviour. \\
\hline Homework & $\checkmark$ & & $\begin{array}{l}\text { Pharmacists could be given reading material on the target behaviour to review at home in advance of, } \\
\text { or following, a training workshop. }\end{array}$ \\
\hline Behavioural contract & $\checkmark$ & & $\begin{array}{l}\text { Pharmacists could be asked to sign a written contract, agreeing to carry out the target behaviour in } \\
\text { their own clinical practice as instructed in a training workshop. }\end{array}$ \\
\hline Action planning & $\checkmark$ & & $\begin{array}{l}\text { As part of a training workshop, pharmacists could be instructed to develop advance plans for how they } \\
\text { will identify and provide MAS to older patients in their own clinical practice. }\end{array}$ \\
\hline $\begin{array}{l}\text { Social support } \\
\text { (unspecified) }\end{array}$ & $\checkmark$ & $\checkmark$ & $\begin{array}{l}\text { Group support could also be encouraged as part of a training workshop and following this using online } \\
\text { platforms. }\end{array}$ \\
\hline $\begin{array}{l}\text { Persuasive } \\
\text { communication/credible } \\
\text { source }\end{array}$ & $\checkmark$ & & $\begin{array}{l}\text { An expert or leader in the field could present arguments in favour of performing the behaviour to } \\
\text { pharmacists at a training workshop. }\end{array}$ \\
\hline Prompts/cues & & $\checkmark$ & $\begin{array}{l}\text { Prompts could be included as part of an electronic adherence support decision-making tool. In } \\
\text { addition, pharmacy support staff could help prompt CPs to provide MAS to older people. }\end{array}$ \\
\hline
\end{tabular}




\begin{tabular}{|l|c|c|l|}
\hline $\begin{array}{l}\text { Restructuring the social } \\
\text { environment }\end{array}$ & $\checkmark$ & $\begin{array}{l}\text { Pharmacists could be advised to restructure their social working environment by involving pharmacy } \\
\text { support staff in the process of identifying potentially non-adherent older patients. }\end{array}$ \\
\hline Social reward & $\checkmark$ & $\checkmark$ & $\begin{array}{l}\text { Pharmacists could be given verbal rewards if there has been sufficient effort/progress in performing } \\
\text { the behaviour during practice sessions or in their own clinical practice. }\end{array}$ \\
\hline Use of imagery & $\checkmark$ & & Visuals (e.g. videos) could be used to deliver other selected BCTs (e.g. demonstration of the behaviour). \\
\hline
\end{tabular}


358 This mixed methods study used the TDF as a 'theoretical lens' to identify key determinants influencing the provision of MAS by pharmacists to older adults prescribed polypharmacy. Following identification of key TDF domains to target for behaviour change using triangulated qualitative and quantitative data, seven domains were mapped across to BCTs using established methods and 18 BCTs were identified as suitable for changing pharmacists' behaviour. ${ }^{12,13}$ This study also explored what community pharmacists in Northern Ireland were doing in their daily practice to support older patients with medication adherence. The finding that only a third of surveyed pharmacists reported frequently asking older patients if they had missed doses of medications reflects findings from an EU-wide survey of 3,196 HCPs, including pharmacists, doctors and nurses, that found only half of HCPs regularly asked patients about missed doses. ${ }^{29}$ In comparison with doctors, pharmacists in the EU survey were five times less likely to ask patients about missed doses (OR: $0.2 ; 95 \% \mathrm{Cl}: 0.17-0.27$ ). This represents a missed opportunity in the community pharmacy setting to identify non-adherent patients and a key area for improvement.

Despite recent emphasis on the importance of tailored approaches to address medication nonadherence ${ }^{45}$, only $38.5 \%$ of pharmacists in Phase 2 of this study reported frequently tailoring adherence solutions to the underlying reasons for non-adherence. One of the most frequently offered adherence solutions was the provision of MDS which reflects findings reported by Mansoor et al. ${ }^{6}$

375 (2014), whereby 95\% of Australian community pharmacists reported that MDS was the most common $376 \stackrel{\sim}{\sim}$ adherence strategy. Although MDS are commonly used, systematic reviews that have explored their 377 effectiveness have reported mixed findings. ${ }^{46-48}$ Furthermore, the UK Royal Pharmaceutical Society 378 has noted that this solution is commonly selected without giving full consideration to the range of adherence solutions available. ${ }^{49}$

This study has highlighted multiple determinants potentially influencing pharmacists' provision of MAS to older adults in their practice. The barriers of inadequate time, pharmacist staff levels (domain: 'Environmental context and resources') and reimbursement (domain: 'Motivation and goals') reflect findings from similar research conducted in Australia. ${ }^{6}$ In Phase 1 (qualitative), a lack of time was the most frequently mentioned barrier whereas in Phase 2 (quantitative) a lack of reimbursement appeared to be the greatest potential barrier with $76.3 \%$ of respondents indicating they did not receive sufficient reimbursement (compared with 59.5\% of respondents who indicated they did not have enough time). A qualitative study conducted in Scotland ${ }^{4}$ has also reported that a lack of time was not seen as the greatest barrier to implementing an adherence intervention, which was in contrast with previously conducted research. ${ }^{50}$ The use of a comprehensive theoretical model of behaviour change in this study has helped go beyond identifying the barriers commonly cited in the 
literature (e.g. time, reimbursement). This theory-based approach has facilitated an exploration of other important areas to target for behaviour change such as pharmacists' skills and approaches to decision-making. For example, although pharmacists were mainly confident in providing MAS, twothirds of survey respondents indicated that they required additional training on techniques that can be used to increase older patients' motivation to adhere (domain: 'Skills'). Over two-thirds of survey respondents also reported that they found it difficult to decide on the best adherence solutions to offer older patients. The 2003 WHO report recognised this difficulty and highlighted that clinical decision-making processes needs to be covered as part of training alongside the development of behavioural tools for HCPs. ${ }^{1}$

Eight theoretical domains in TDF1 were identified as important in the context of the target behaviour. Although the domain 'Environmental context and resources' was identified as a key target domain, it should be noted that some of the barriers identified under this domain (including a lack of access to medical records and inadequate pharmacist staffing levels) would be beyond the scope of future research studies to target directly. However, the BCTs 'Restructuring the social environment' and 'Prompts and cues' were selected as the involvement of support staff in the process of identifying non-adherent patients and prompting pharmacists to intervene could improve the provision of MAS. Four domains ('Beliefs about capabilities', 'Beliefs about consequences', 'Emotion', 'Nature of the behaviours') were not selected as important as they were not frequently coded in Phase 1 and Phase 2 did not highlight potential barriers/facilitators to the target behaviour within these domains. In relation to pharmacists' 'Beliefs about capabilities', the qualitative findings suggest that this stems from their level of skills training and so focusing on the latter appears to be of greater importance. The quantitative component of this study confirmed that the majority of pharmacists were confident in providing adherence support but lacked the skills required to motivate patients to change their behaviour. In relation to pharmacists' 'Beliefs about the consequences', these were discussed less frequently than other domains in Phase 1 and pharmacists reported having awareness of the positive consequences of providing MAS. In addition, no barriers were identified under this domain in Phase 2. Emotions were rarely discussed in the context of the target behaviour in Phase 1 and no barriers were identified under the 'Emotion' domain in Phase 2 which confirmed this finding. The overall behaviour was not seen as automatic and instead requires planning and consideration and consequently, the 'Nature of the behaviours' domain was not deemed important in this context. Although the domain 'Social, professional role and identity' was identified as important in this context, it was not selected as a key target domain for behaviour change. Pharmacists largely considered the target behaviour to be part of their role, although they recognised that an inability to prescribe and lack of integration in the primary healthcare team were potential barriers to the provision of MAS. 
Changing the role of pharmacists in the primary care setting would require major policy and organisational changes which was deemed to be beyond the scope of future research studies.

The study has highlighted the usefulness of a mixed methods approach in selecting domains that are important to target for behaviour change. The majority of studies that have previously employed the TDF to select target domains have relied on qualitative data from interviews and used frequency counts as a crude measure of a domain's importance. ${ }^{51}$ This study takes this a step further by providing quantitative data to support the qualitative findings and also identify domains which are likely to be important but are infrequently coded in qualitative research (e.g. 'Behavioural regulation' in the current study).

This study has identified $18 \mathrm{BCTs}$ that can be delivered to pharmacists as part of a training package or as implementation strategies to enhance the provision of MAS in community pharmacies. These BCTs will be tested in the next phase of the project which involves the pilot testing of theory-based patienttargeted adherence intervention that will be delivered in the community pharmacy setting. To the best of our knowledge, this is the first mixed-methods study to detail the steps undertaken in identifying key TDF domains to target and selection of BCTs which will form the active ingredients of future behaviour change intervention for community pharmacists. As noted in guidance published by Atkins et al. ${ }^{51}$ on the use of TDF, TDF methodology is evolving to include quantitative approaches and the current study contributes to the growing literature on the use of mixed methods TDF-based approaches.

\section{Strengths and limitations}

445 To the authors' best knowledge, this is the first study to make use of the TDF as a theoretical lens to explore the provision of MAS by community pharmacists to older adults prescribed polypharmacy. A

447 key strength of this study was the triangulation of data from both qualitative and quantitative approaches which helps to increase the generalisability of findings. The study followed guidance from the MRC which recommends incorporating a theoretical base when developing interventions designed to change behaviours, including training packages for HCPs. ${ }^{52}$ The qualitative methods employed in this study reflect the methods advocated in recently published guidance on how to use the TDF. ${ }^{51}$ As a limitation of this study, the low response rate (27.4\%) achieved for the survey (Phase 2) should be noted. This response rate was comparable to the response rate (27.6\%) obtained in a survey on MAS that was mailed to 500 community pharmacists in New South Wales, Australia. ${ }^{6}$ Similarities in terms of gender, age groups and post-graduate qualifications were observed between the sample of survey respondents and all pharmacists who were registered with the PSNI at the time of the study.

457 However, it is important to note that there was a slight underrepresentation of females and potential 
over-representation of those in managerial roles. The potential for social desirability bias must also be noted, as pharmacists were made aware of the latest guidance on supporting patients with medication

460 adherence that had been published by NICE. ${ }^{2}$ By using an anonymous self-administered questionnaire 461 which included both positive and negatively phrased items it is hoped that the level of social desirability bias in the survey was minimal.

\section{3}

464

465

466

467

468

469

470

471

472

473

474

\section{Conclusions}

This study involved a mixed methods approach to explore community pharmacists' clinical behaviour, in terms of providing MAS to older adults prescribed polypharmacy. A range of barriers and facilitators were perceived to influence the target behaviour including insufficient reimbursement, lack of relevant skills, and social support from other HCPs. Triangulation of qualitative and quantitative findings facilitated the selection of seven key theoretical domains that could be targeted for behaviour change. Established methods were employed to map key TDF domains to BCTs, and using group consensus methods, 18 BCTs were identified as applicable to the target audience and behaviour. As part of future research these BCTs will be delivered as part of a pilot study of a patient-targeted intervention which will include a training package for community pharmacists.

\section{Declarations of interest}

None.

\section{$475 \cong$ Authors' contributions}

476 XXXX: Conceptualisation; Investigation; Project administration; Formal analysis; Funding acquisition;

477 Writing - original draft.

478 XXXX: Conceptualisation; Supervision; Formal analysis; Funding acquisition; Writing - review \& 479 editing.

480 XXXX: Conceptualisation; Supervision; Formal analysis; Funding acquisition; Writing - review \& 481 editing.

482 Acknowledgements

483 The authors would like to acknowledge all of the community pharmacists who participated in 484 interviews or responded to the survey.

\section{$485 \quad$ Funding}

486 This work was supported by the Harold and Marjorie Moss Charitable Trust Fund and by the 487 Department of Employment and Learning, Northern Ireland. 
1. Sabate E. Adherence to Long-Term Therapies: Evidence for Action. 2003 [Online] World

Health Organisation. Available from:

http://www.who.int/chp/knowledge/publications/adherence_report/en/. Last accessed: 29 November 2019.

2. National Institute for Health and Clinical Excellence. NICE guidance: Medicines adherence: Involving patients in decisions about prescribed medicines and supporting adherence. 2009 [Online]. Available from: https://www.nice.org.uk/guidance/cg76. Last accessed: 29 November 2019.

3. Huston SA. Pharmacist provision of medication adherence services: More implementation and persistence research needed. Res Soc Adm Pharm. 2015;11:721724

4. Bacci JL, Bacci JL, McGrath SH, Pringle JL, Maguire MA, McGivney MS. Implementation of targeted medication adherence interventions within a community chain pharmacy practice: The Pennsylvania Project. J Am Pharm Assoc. 2014;54:584-593.

5. Lowrie R, Johansson L, Forsyth P, Bryce SL, McKellar S, Fitzgerald N. Experiences of a community pharmacy service to support adherence and self-management in chronic heart failure. Int J Clin Pharm. 2014;36:154-162.

6. Mansoor SM, Aslani P, Krass I. Pharmacists' attitudes and perceived barriers to provision of adherence support in Australia. Int J Clin Pharm. 2014;36:136-144.

7. Marquis J, Schneider MP, Spencer B, Bugnon O, Du Pasquier. Exploring the implementation of a medication adherence programme by community pharmacists: a qualitative study. Int J Clin Pharm. 2014;36:1014-1022.

8. Mansoor SM, Krass I, Costa DSJ, Aslani P. Factors influencing the provision of adherence support by community pharmacists: A structural equation modeling approach. Res Soc Adm Pharm. 2015;11:769-783.

9. Wright D. A rapid review of evidence regarding clinical services commissioned from community pharmacies Commissioned by the Chief Pharmaceutical Officer for England to inform the Murray Review of clinical services in community pharmacy. 2016 [Online]. Available from: https://www.england.nhs.uk/commissioning/wpcontent/uploads/sites/12/2016/12/ rapid-evdnc-rev-dec-16.pdf. Last accessed: 29 November 2019.

10. Business Services Organisation. Targeted Medicines Use Review Service specification (Version 2). 2014 [Online]. Available from:

http://www.hscbusiness.hscni.net/pdf/Targeted_Medicines_Use_Review_service_specif ication.pdf. Last accessed: 29 November 2019.

11. Michie S, Johnston M, Abraham C, Lawton R, Parker D, Walker A. Making psychological theory useful for implementing evidence based practice: a consensus approach. Qual Saf Heal Care. 2005;14:26-33.

12. Michie S, Johnston M, Francis J, Hardeman W, Eccles M From theory to intervention: mapping theoretically derived behavioural determinants to behaviour change techniques. Appl Psychol. 2008;57:660-680.

13. Cane J, Richardson M, Johnston M, Ladha R, Michie S. From lists of behaviour change techniques (BCTs) to structured hierarchies: comparison of two methods of developing a hierarchy of BCTs. Br J Health Psychol. 2015;20:130-150.

14. Michie S, Johnston M, Abraham C, Francis J, Hardeman W, Eccles, M. BCT taxonomy. Starter Pack: for trainees. Available from: http://www.bct-taxonomy.com/pdf/ StarterPack.pdf. Last accessed: 29 November 2019.

15. Francis JJ, O'Connor D, Curran J. Theories of behaviour change synthesised into a set of theoretical groupings: introducing a thematic series on the theoretical domains framework. Implement Sci. 2012;7:35. 
16. Brotherton JML, Leask J, Jackson C, McCaffery K, Trevena L. National survey of general practitioners experience of delivering the national human papillomavirus vaccination program. Sex Health. 2010;7:291-298.

17. Dyson J, Lawton R, Jackson C, Cheater F. Does the use of a theoretical approach tell us more about hand hygiene behaviour? The barriers and levers to hand hygiene. J Infect Prev. 2011;12:17-24.

18. Clarkson JE, et al. The translation research in a dental setting (TRiaDS) programme protocol. Implement Sci. 2010;5:57.

19. O'Cathain A, Murphy E, Nicholl J. Three techniques for integrating data in mixed methods studies. BMJ. 2010;341:c4587.

20. Cane J, O'Connor D, Michie S. Validation of the theoretical domains framework for use in behaviour change and implementation research. Implement Sci. 2012;7.

21. Huijg JM, Gebhardt WA, Crone MR, Dusseldorp E, Presseau J. Discriminant content validity of a theoretical domains framework questionnaire for use in implementation research. Implement Sci. 2014;9:11.

22. Tong A, Sainsbury P, Craig J. Consolidated criteria for reporting qualitative research (COREQ): a 32- item checklist for interviews and focus group. Int J Qual Heal Care. 2007;19:349-357.

23. Removed for blinding purposes

24. Atkinson R, Flint J. Accessing Hidden and Hard-to-Reach Populations: Snowball Research Strategies. Soc Res Updat. 2001;33:1-4.

25. Fusch PI, Ness LR. Are we there yet? Data saturation in qualitative research. Qual Rep. 2015;20:1408-1416.

26. Hardigan PC, Popovici I, Carvajal MJ. Response rate, response time, and economic costs of survey research: A randomized trial of practicing pharmacists. Res Soc Adm Pharm. 2016;12:141-148.

27. Neuman WL. Social Research Methods: Qualitative and Quantitative Approaches. 7th Edition. 2013. Harlow: Pearson Education Limited.

28. Bright DR, Lengel AJ, Powers MF. Pharmacists' perceptions of barriers to implementing medication therapy management and the role of pharmacy technicians in overcoming the barriers. J Pharm Technol. 2009;25:361-367.

29. Clyne W, Comfort M, McLachlan S, et al. A multinational cross-sectional survey of the management of patient medication adherence by European healthcare professionals. BMJ Open. 2016; 6. doi: 10.1136/bmjopen-2015-009610.

30. Cane J, O'Connor D, Michie S. Validation of the theoretical domains framework for use in behaviour change and implementation research. Implement Sci. 2012;7:37.

31. Amemori M, Michie S, Korhonen T, Murtomaa H, Kinnunen TH. Assessing implementation difficulties in tobacco use prevention and cessation counselling among dental providers. Implement Sci. 2011;6:1-10.

32. Beenstock J, Sniehotta FF, White M, Bell R, Milne EM, Araujo-Soares V. What helps and hinders midwives in engaging with pregnant women about stopping smoking? A crosssectional survey of perceived implementation difficulties among midwives in the North East of England. Implement Sci. 2012;7:36.

33. Manikam L, Manikam L, Hoy A, et al. What drives junior doctors to use clinical practice guidelines? A national cross-sectional survey of foundation doctors in England \& Wales. BMC Med Educ. 2015;15:227.

34. McParlin C, Bell R, Robson SC, Muirhead CR, Araújo-Soares V. What helps or hinders midwives to implement physical activity guidelines for obese pregnant women? A questionnaire survey using the Theoretical Domains Framework. Midwifery. 2016;49: 110-116. 
35. Huijg JM, Gebhardt WA, Dusseldorp E, et al. Measuring determinants of implementation behavior: psychometric properties of a questionnaire based on the theoretical domains framework. Implement Sci. 2014;9:33.

36. Taylor N, Parveen S, Robins V, Slater B, Lawton R. Development and initial validation of the Influences on Patient Safety Behaviours Questionnaire. Implement Sci. 2013;8:81.

37. Gale NK, Heath G, Cameron E, Rashid S, Redwood S. Using the framework method for the analysis of qualitative data in multi-disciplinary health research. BMC Med Res Methodol. 2013;13:117.

38. Clason DL, Dormody TJ. Analyzing data measured by individual Likert-type items. J Agric Educ. 1994;35:31-35.

39. Bolarinwa O. Principles and methods of validity and reliability testing of questionnaires used in social and health science researches. Niger Postgrad Med J. 2015;22:195.

40. Bryman A. Social research methods. 2013. Oxford: Oxford University Press.

41. Boone HNJ, Boone DA. Analyzing Likert data. J Ext. 2012;50:30.

42. Sullivan GM, et al. Likert scales: dispelling the confusion. Electron J Bus Res Methods. 2013;11:1-2.

43. Jamieson S. Likert scales: How to (ab)use them. Med Educ. 2004;38(12):1217-1218.

44. Michie $\mathrm{S}$, et al. The behavior change technique taxonomy (v1) of 93 hierarchically clustered techniques: building an international consensus for the reporting of behavior change interventions. Ann Behav Med. 2013;46:81-95.

45. Easthall C, Barnett N. Using theory to explore the determinants of medication adherence; moving away from a one-size-fits-all approach. Pharmacy. 2017. doi:10.3390/pharmacy5030050.

46. Mahtani KR, Heneghan CJ, Glasziou PP, Perera R. Reminder packaging for improving adherence to self-administered long-term medications. Cochrane Database Syst Rev. 2011:9-11.

47. Watson SJ, Aldus CF, Bond C, Bhattacharya D. Systematic review of the health and societal effects of medication organisation devices. BMC Health Serv Res. 2016;16:202.

48. Boeni F, Spinatsch E, Suter K, Hersberger KE, Arnet I. Effect of drug reminder packaging on medication adherence: a systematic review revealing research gaps. Syst Rev. 2014;3:29.

49. The Royal Pharmaceutical Society. Improving patient outcomes: The better use of multicompartment compliance aids. 2013 [Online]. Available at: https://www.rpharms.com/Portals/0/RPS document library/Open access/Support/toolkit/rps-mca-july-2013.pdf. Last accessed: 28 November 2019.

50. Osborne MA, Snyder ME, Hall DL, Coley KC, McGivney MS. Evaluating Pennsylvania pharmacists' provision of community-based patient care services to develop a statewide practice network. Inov Pharm. 2011;2:61.

51. Atkins L, Francis J, Islam R, et al. A Guide to using the Theoretical Domains Framework of behaviour change to investigate implementation problems. Implement Sci. 2017:7.

52. Medical research council. Developing and evaluating complex interventions: new guidance. 2008 [Online]. Available from: https://www.mrc.ac.uk/documents/pdf/complex-interventions-guidance/. Last accessed: 29 November 2019. 